самые высокие энергетические уровни с минимальной энергией связи с последующим восполнением энергии за счёт космического вакуума.

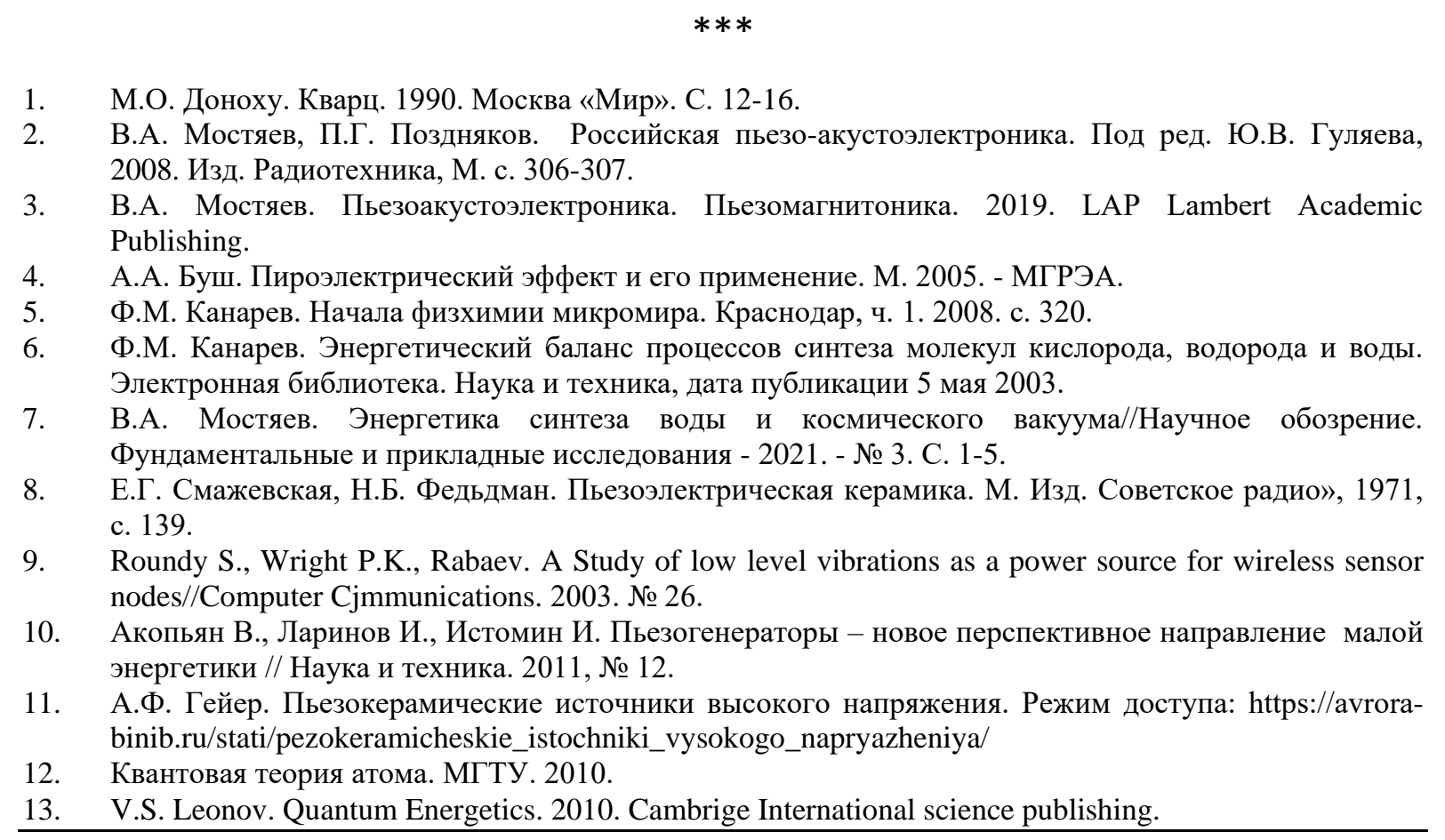

Сельдушова Д.Д., Нехаева Н.Е.

\title{
География рекреационного туризма в регионах Приволжского федерального округа
}

Национальный исследовательский Мордовский государственный университет им. Н.П. Огарёва (Россия, Саранск)

doi: $10.18411 / \mathrm{j}-08-2021-22$

\section{Аннотация}

В статье рассматриваются вопросы географии рекреационного туризма в регионах Приволжского федерального округа с точки зрения сезонности.

Ключевые слова: рекреационный туризм, Приволжский федеральный округ, рекреация, география, горнолыжные курорты, зимняя рекреация, летняя рекреация, сплавы, купание, пешие походы.

\section{Abstract}

The article deals with the geography of recreational tourism in the regions of the Volga Federal District from the point of view of seasonality.

Keywords: recreational tourism, Volga Federal District, recreation, geography, ski resorts, winter recreation, summer recreation, rafting, swimming, hiking.

Рекреационный туризм - это передвижение людей в свободное время в целях отдыха, необходимого для восстановления физических и душевных сил человека, посредством рекреационных ресурсов: рельефа, водных объектов и почвеннорастительного покрова, биоклимата, уникальных природных лечебных ресурсов [1].

Географию рекреационного туризма в Приволжском федеральном округе рассмотрим с точки зрения сезонности. 
Зимняя рекреация в регионах Приволжского федерального округа (далее ПФО) рассматривается нами в контексте развития горнолыжных курортов и, в совокупности, горнолыжных баз, центров и комплексов (рисунок 1).

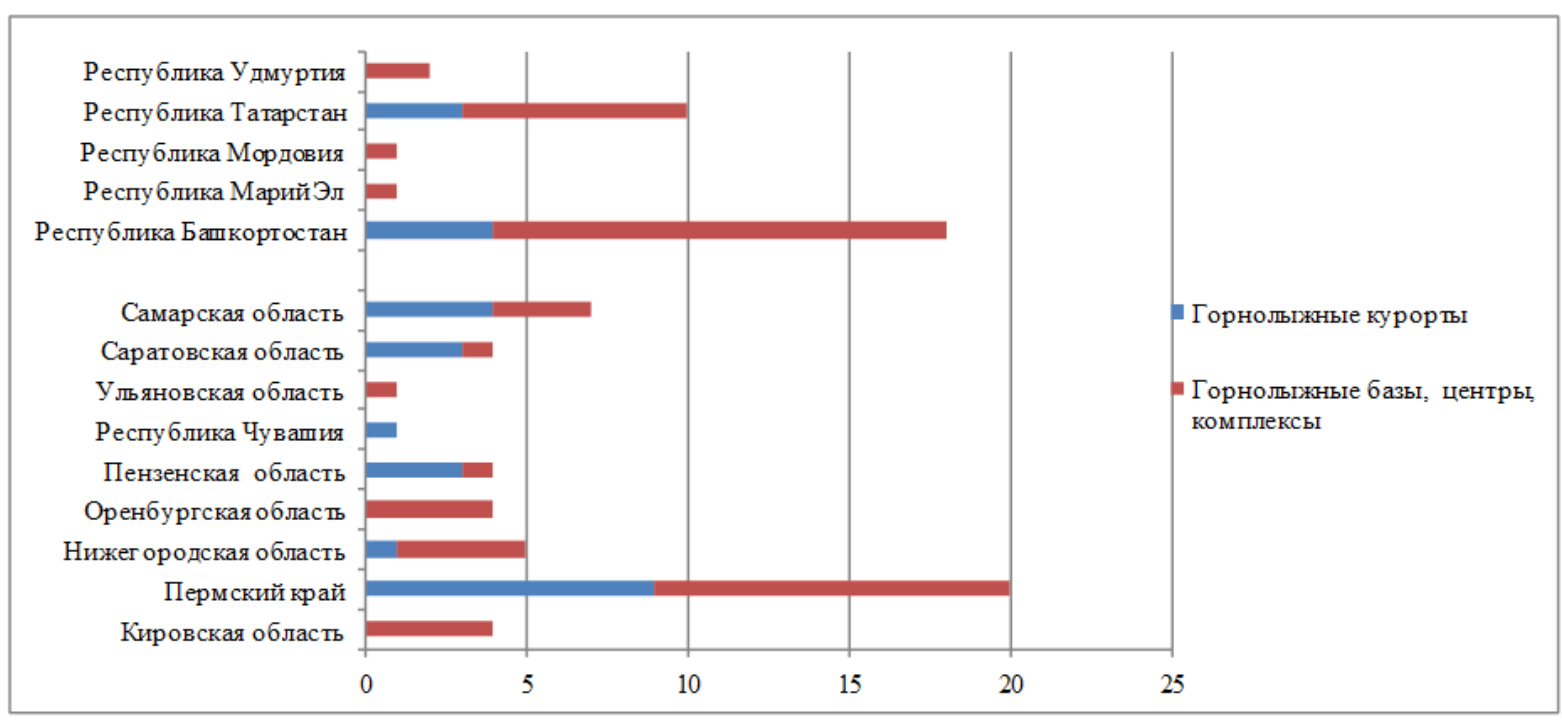

Рисунок 1 - Развитие зимнего рекреационного туризма в регионах Приволжского федерального округа

В округе насчитывается около 63 объектов для зимней рекреации, общей протяженностью трасс в 40 км, горнолыжные курорты обслуживают 31 подъемник. Крупнейшие и самые значимые в туризме горнолыжные курорты, и центры Приволжского федерального округа расположены в регионах, прилежащих к Уралу Пермском крае и Республике Башкортостан, а также в Республике Татарстан Самарской области [2].

В списке самых посещаемых горнолыжных курортов Приволжского федерального округа лидером является горнолыжный курорт «Абзаково», также он является и самым высоким - простирается до высоты 1170 м. Период горнолыжного катания: середина ноября - начало мая. Абзаково - это один из самых современных горнолыжных комплексов в России, соответствующий мировым стандартам качества трасс (что подтверждено соответствующими сертификатами FIS и массой ежегодно проводимых соревнований).

Одним из самых популярных горнолыжных курортов в республике Башкортостан считается горнолыжный центр «Металлург-Магнитогорск». Этот многофункциональный курорт располагается между одноименным городом Магнитогорск, и своим горнолыжным «соседом» - курортом «Абзаково». Отличительной особенностью расположения курорта является тот фактор, что он находится непосредственно на берегу живописного озера Банное. Со всех сторон горнолыжный центр «Металлург-Магнитогорск» окружен горным массивом и лесами, природное богатство и разнообразие также привлекают к посещению горнолыжного центра.

Еще одним из самых посещаемых горнолыжных комплексов в ПФО является горнолыжный комплекс «Губаха», который находится в поселке Первомайский города Губаха Пермского края. Сюда охотно приезжают любители лыжных видов спорта почти из всех уголков России, поскольку горнолыжный комплекс предлагает 17 трасс разного уровня сложности и протяженности от 80 до 2600 м.

Горнолыжный комплекс «Красная Глинка» расположен недалеко от центра Самары, в поселке Красная Глинка. Сокольи горы здесь спускаются к Волге, создавая базу для устройства горнолыжных трасс. На противоположном берегу реки поднимается горная цепь Жигули, на которую открывается отличный вид. 
Основой для летней рекреации в ПФО являются водные ресурсы округа (рисунок 2), которые используются в качестве сплавов по рекам/озерам, купания в реках/озерах. Также летняя рекреация связана с пешими туристскими походами (более 24 ч), организуемыми зачастую по возвышенностям, в ООПТ и к водоемам.

Из рисунка 2 видно, что во всех регионах преимущественно выделяются места, оборудованные для купания, что объясняется присутствием в регионе густой речной и озерной сети, водохранилищ, принадлежащих в основном главной водной артерии региона реке Волге. Большое количество мест для купания в восточных регионах ПФО объясняется их отношением к бассейнам не только Волги, но и к рекам Урала.

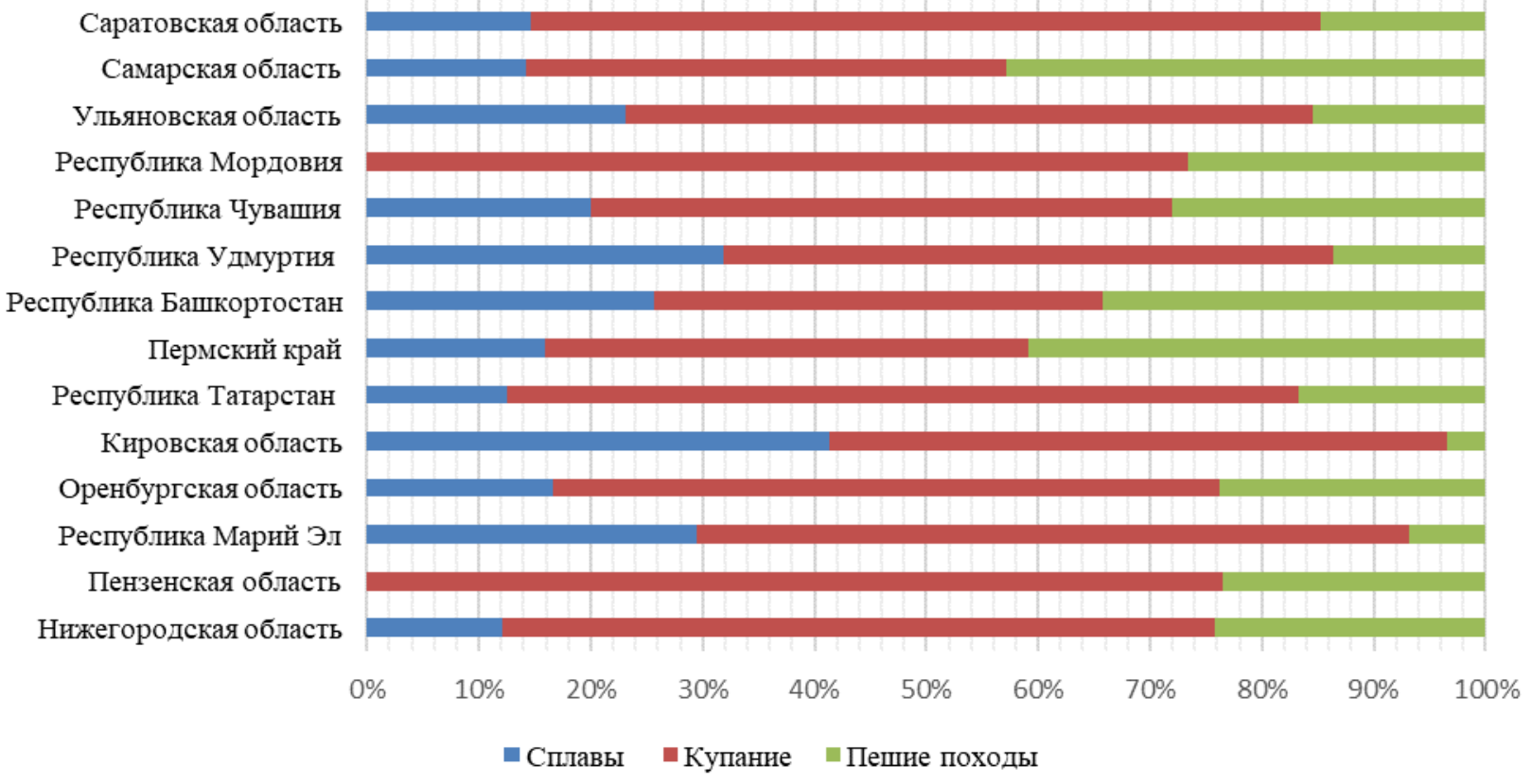

Рисунок 2 - Виды и количество летних видов рекреации в регионах Приволжского федерального округа

Сплавы развиты в регионах с крупными реками и озерами. Например, Сплав по р. Немде (Кировская область, 3 дня). За 2 дня туристы побывают в «Вятской Швейцарии» - самые живописные и уникальные достопримечательности Кировской области, расположенные в Советском районе.

Долина реки Немды, скальный массив «Камень», скала Часовой, Береснятский водопад, Буржатский утес и расщелины. Уровень сложности: легкий, физ. подготовка не требуется. Протяженность маршрута: по воде - 25 км, пеший - около 10 км.

Пешие походы продолжительностью более 24 ч, организуются в регионах Северного и Южного Урала (Республика Башкортостан и Пермский край, регионы Оренбургской области), в остальных регионах ПФО пеший туризм развит в местах с долинами рек, часто меняющимися пейзажами, в основном такие походы организуют в ООПТ округа. Например, «Поход на гору Малиновая 1152 м и Синие скалы» 2 дня/1 ночь (Оренбургская область). Гора Малиновая (Малиновка, Елэкташ) имеет три вершины с максимальной высотой 1152 м над уровнем моря. С вершин Малиновой открывается красивый вид на окрестности. С одной стороны виден весь Белорецк, а с другой можно увидеть высшую точку Южного Урала - гору Ямантау (1640). Дорога постепенно набирает высоту и поднимается прямо под скалы. Маршрут не сложный и доступен любому туристу [3].

Рекреационный туризм включает в себя и посещение санаторно-курортных организаций, причем в данном случае рекреация рассматривается как круглогодичная. 
Всего на территории ПФО расположено 399 санаторно-курортных организаций. По количеству санаторно-курортных организаций в 2020 г. ПФО занимает третье место среди других регионов России. Самое большое количество организаций насчитывается в Республике Башкортостан - 74 организации, что составляет 18,55 \% [4]. Анализ мест в санаторно-курортных организациях ПФО позволяет сделать следующие выводы. Лидирующим регионом по числу также является Республика Башкортостан, 11345 мест (рисунок 3).

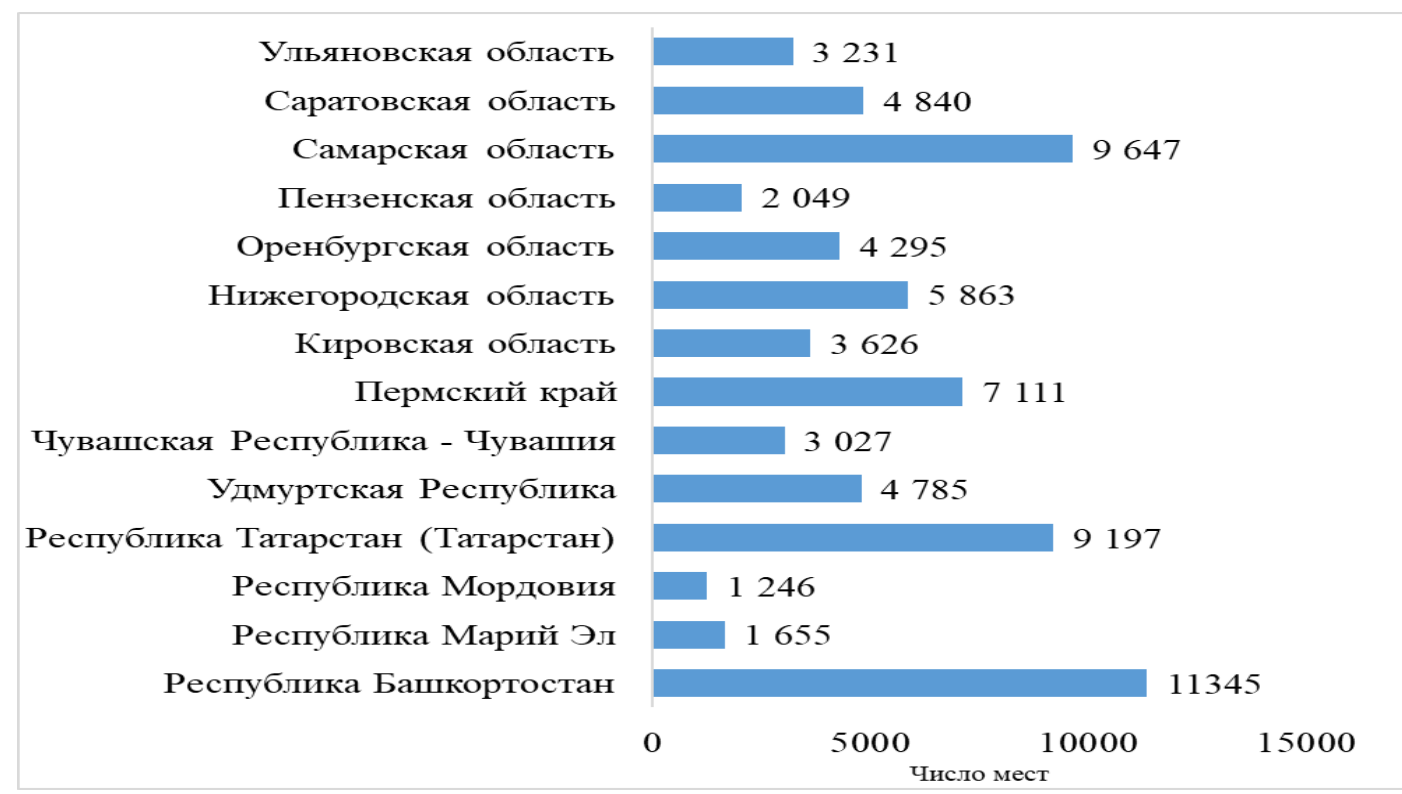

Рисунок 3 - Число мест в санаторно-курортных организащиях в 2020 году на территории Приволжского федерального округа [4]

В процентном соотношении количество мест в Башкортостане составляет 15,5 \% от всего числа мест во всем Приволжском федеральном округе. Республика Татарстан и Пермский край так же имеют большое количество мест. Это объясняется достаточно большим количеством санаторно-курортных организаций. $\mathrm{C}$ самым низким показателем (число мест в санаторно-курортных организациях) отмечены следующие регионы: республики Мордовия и Марий Эл, Пензенская область.

Таким образом, рекреационная деятельность в различных субъектах ПФО представлена неоднородно и связана она, в первую очередь, с природными предпосылками в регионах округа. Зимняя рекреация представлена в регионах с высокогорным рельефом местности, а летняя рекреация во многом зависит от имеющихся крупных водных артерий, наличия живописной местности с разнообразным рельефом, особо охраняемых природных территорий, по которым проходит значимая часть всех пеших маршрутов. Круглогодичный отдых организован в санаторно-курортных организациях, наличие которых во многом обусловлено бальнеологическими, грязевыми или климатическими ресурсами.

1. Исаченко Т.Е. Рекреационное природопользование: учебник / Т.Е. Исаченко, А.В. Косарев. Москва: Юрайт, 2019. - 268 с. - ISBN 978-5-534-11383-9. - Текст: непосредственный.

2. Национальный туристский портал: сайт. - Москва, 2021. - URL: https://russia.travel/ (дата обращения: 21.07.2021). - Режим доступа: для авториз. пользователей. - Текст: электронный.

3. Федеральное агентство по туризму РФ: сайт. - Москва, 2021. - URL: http://www.russiatourism.ru (дата обращения: 26.04.2021). - Режим доступа: для авториз. пользователей. - Текст: электронный.

4. Число санаторно-курортных организаций. - Текст: электронный // Единая межведомственная информационно-статистическая система: официальный сайт. - 2021. - URL: https://fedstat.ru/indicator/42106/ (дата обращения: 21.07.2021). 